\title{
Performance and safety of femoral central venous catheters in pediatric autologous peripheral blood stem cell collection
}

\author{
Laura Cooling1 (D) | Sandra Hoffmann ${ }^{1}$ | Dawn Webb' | Chisa Yamada ${ }^{1}$ | \\ Robertson Davenport ${ }^{1}$ | Sung Won Choi ${ }^{2}$
}

${ }^{1}$ Department of Pathology, Blood and

Marrow Transplantation Program, University

of Michigan, Ann Arbor, Michigan

${ }^{2}$ Department of Pediatric, Blood and Marrow

Transplantation Program, University of

Michigan, Ann Arbor, Michigan

\section{Correspondence}

Laura Cooling MD, MS, Associate Director, Transfusion Medicine, Director, Cell Therapy Laboratory, University of Michigan Hospitals, 2F225 UH-Blood Bank, Box 0054, 1500 East Medical

Center Drive, Ann Arbor,

MI 48109-0054.

Email: lcooling@med.umich.edu

\begin{abstract}
Introduction: Autologous peripheral blood hematopoietic progenitor cell collection (A-HPCC) in children typically requires placement of a central venous catheter (CVC) for venous access. There is scant published data regarding the performance and safety of femoral CVCs in pediatric A-HPCC.

Methods: Seven-year, retrospective study of A-HPCC in pediatric patients collected between 2009 and January 2017. Inclusion criteria were an age $\leq 21$ years and AHPCC using a femoral CVC for venous access. Femoral CVC performance was examined by CD34 collection rate, inlet rate, collection efficiency (MNC-FE, CD34$\mathrm{FE}$ ), bleeding, flow-related adverse events (AE), CVC removal, and product sterility testing. Statistical analysis and graphing were performed with commercial software.

Results: A total of 75/119 (63\%) pediatric patients (median age 3 years) met study criteria. Only $16 \%$ of children required a CVC for $\geq 3$ days. The CD34 collect rate and CD34FE was stable over time whereas MNC-FE decreased after day 4 in $80 \%$ of patients. CD34-FE and MNC-FE showed inter- and intra-patient variability over time and appeared sensitive to plerixafor administration. Femoral CVC showed fewer flow-related AE compared to thoracic $\mathrm{CVC}$, especially in pediatric patients $(6.7 \%$ vs. $37 \%, P=0.0005$; $\mathrm{OR}=0.12$ (95\%CI: 0.03-0.45). CVC removal was uneventful in 73/75 (97\%) patients with hemostasis achieved after 20-30 min of pressure. In a 10-year period, there were no instances of product contamination associated with femoral CVC colonization.
\end{abstract}

Conclusion: Femoral CVC are safe and effective for A-HPCC in young pediatric patients. Femoral CVC performance was maintained over several days with few flow-related alarms when compared to thoracic CVCs.

\section{K E Y W O R D S}

catheter, pediatric, stem cell collection

This article was published online on May 9, 2017. After online publication, the age of the inclusion criteria in the Abstract and the flow statistic reported in the first row, sixth column of Table 5 was corrected. This notice is included in the online and print versions to indicate that both have been corrected on May 19, 2017.

Abbreviations: AE, adverse event; A-HPCC, autologous peripheral blood hematopoietic cell collection; BV, blood volume; CVC, central venous catheter; FE, fractional collection efficiency; G-CSF, granulocyte-colony stimulating factor; GM-CSF, granulocyte-macrophage-colony stimulating factor; PIV, peripheral intravenous catheter; s, second. 


\section{1 | INTRODUCTION}

Adequate venous access can be challenging in pediatric patients undergoing autologous peripheral blood hematopoietic progenitor cell collection (A-HPCC). Most pediatric patients require a central venous catheter (CVC) to establish and maintain adequate blood flow for cell separation. ${ }^{1,2}$ In older children and adults requiring CVC access, the preferred catheter is a double-lumen, polyurethane CVC placed in the subclavian vein or internal jugular. ${ }^{3}$ In very small children, however, the rigidity and size of polyurethane CVC relative to patient anatomy increases the difficulty and potential risks associated with thoracic CVC. ${ }^{1}$ To avoid polyurethane CVCs, some centers have used soft, silicone-type CVC for pediatric A-HPCC. Unfortunately, silicone-based catheters are prone to collapse, with an increasing risk of mechanical occlusion at small sizes. ${ }^{1}$ In addition, A-HPCC using some tunneled silicone-type catheters still requires a peripheral intravenous catheter (PIV) for return to avoid recirculation due to the close proximity of the draw and return lumens. ${ }^{4}$ Finally, long-term catheters have in increasing risk of infection, catheter dysfunction, and thrombosis in $10-74 \%$ of patients. ${ }^{5-8}$

Our institution has routinely used short-term femoral CVC in young pediatric patients undergoing A-HPCC. Patients undergo femoral line placement the morning of their first scheduled A-HPCC, followed by line removal 6-24 h after their last procedure. In critically ill children, femoral CVCs have a low rate of insertion-related complications, but are reported to have a higher rate of mechanical obstruction and thrombosis. ${ }^{9} 10$ Likewise, at least one institution has anecdotally reported a high rate of catheter occlusion during A-HPCC in children younger than 3 years of age. ${ }^{11}$ Femoral CVCs are also associated with a higher incidence of infection. ${ }^{12,13}$ As a quality assurance project, we performed a 7 year review of femoral CVC performance on CD34 collection, product sterility, and procedure-related adverse events (AE) in pediatric patients undergoing A-HPCC.

\section{2 | MATERIALS AND METHODS}

\section{1 | Patients and study design}

The study was a 7-year retrospective review of A-HPCC in pediatric patients at the University of Michigan between January 1, 2009 and January 31, 2017: Earlier collections were excluded due to the lack of consistent peripheral CD34 counts after Day 1 and incomplete documentation of catheter-related issues during leukapheresis. Inclusion criteria included: (1) age $\leq 21$ years at the time of A-HPCC; (2) a double-lumen, femoral CVC for venous access; and (3) leukapheresis using either the COBE Spectra ${ }^{\circledR}$ or SPECTRA Optia and CMNC program (TerumoBCT, Lakewood, CO). Patients collected on the SPECTRA Optia using the MNC program were excluded because of internal data showing decreased collection efficiencies in children requiring a blood prime. ${ }^{14}$ Among 119 pediatric patients who underwent A-HPCC, 75 met inclusion criteria. Forty-four patients were excluded due to alternative CVCs ( $n=19$ : 10 subclavian and 9 internal jugular), peripheral IV access $(n=18)$, and collection using the SPECTRA Optia and MNC program $(n=7)$.

Primary data elements included: patient demographics (age, weight, diagnosis); mobilization (chemotherapy, growth factors [Granulocyte colony-stimulating factor, GCSF; Granulocyte-macrophage colony-stimulating factor, GM-CSF], plerixafor); laboratory studies (peripheral blood WBC, platelet count, MNC and CD34 counts) number of leukapheresis procedures, fractional collection efficiencies (FE), inlet rate $(\mathrm{mL} /$ minute, $\mathrm{mL} /$ minute $/ \mathrm{kg}$ ) and product characteristics (cell yields, sterility testing). Catheter-specific information included a review of the operative procedure note for CVC size, manufacturer and adverse events (AE). Catheter-related issues impacting A-HPCC were identified from the procedure record and product master file. As previously published, ${ }^{15}$ CVC-related AEs during A-HPCC were defined as bleeding; catheter dysfunction requiring repeated flushing, line reversal, instillation of anti-thrombolytics, or use of alternate venous access; slow inlet rate $(<0.7$ $\mathrm{mL} \min ^{-1} \mathrm{~kg}^{-1}$ ); difficulty in establishing or maintaining an interface, circuit clotting and early termination of procedures. Femoral CVC performance was compared to a small cohort of pediatric $(n=19)$ and adult myeloma patients $(n=19)$ who underwent A-HPCC with thoracic CVC.

\subsection{Femoral CVC}

Patients underwent femoral CVC placement under general anesthesia the morning of their first scheduled leukapheresis collection. Catheter care was per institutional guidelines. ${ }^{16}$ Following each apheresis session, catheter lines were flushed with $5 \mathrm{~mL}$ saline, followed by heparin $\left(1: 1000 \mathrm{U} \mathrm{mL}^{-1}\right.$, $0.9-1.3 \mathrm{~mL}$ fill volume) and then capped. Femoral CVCs were removed within 6-24 h of the last A-HPCC. Criteria

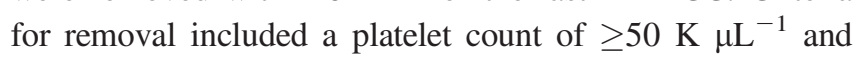
correction of coagulation studies to assure the absence of residual citrate effect. Patients with a post-procedure platelet

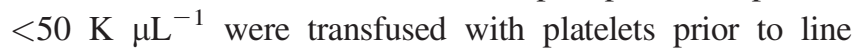
removal. Lines were removed at the patient bedside by Blood and Marrow Transplant (BMT) staff or in the operating room in coordination with other procedures. Following removal, patients were observed for a minimum of $1 \mathrm{~h}$ with activity restrictions for at least $6 \mathrm{~h}$. Patients were advised to avoid bathing or showering for up to $24 \mathrm{~h}$ after CVC removal. 
TABLE 1 Patient demographics

\begin{tabular}{|ll}
\hline Variable & No. patients (\%) \\
\hline No. patients & 75 \\
\hline Sex $(\mathrm{M} / \mathrm{F})$ & $37 / 38$ \\
\hline $\begin{array}{l}\text { Age, years } \\
\text { (median, range) }\end{array}$ & $4.8 \pm 4.0(3,0.8-17)$ \\
$\quad \leq 2$ years $(\%)$ & $19(26 \%)$ \\
$\leq 5$ years $(\%)$ & $52(70 \%)$ \\
$>5$ years $(\%)$ & $22(30 \%)$ \\
\hline $\begin{array}{l}\text { Weight, } \mathrm{kg} \\
(\text { median, range) }\end{array}$ & $21.8 \pm 15.8(16.4,8-97)$ \\
$\leq 10 \mathrm{~kg} \mathrm{( \% )}$ & $8(11 \%)$ \\
$\leq 20 \mathrm{~kg} \mathrm{( \% )}$ & $51(69 \%)$ \\
$>20 \mathrm{~kg}(\%)$ & $23(31 \%)$
\end{tabular}

Primary diagnosis $(\%)$

$\begin{array}{ll}\text { Neuroblastoma } & 45(60 \%) \\ \text { CNS malignancy } & 17(23 \%) \\ \text { Lymphoma } & 5(7 \%) \\ \text { Hepatoblastoma } & 2(2.7 \%) \\ \text { Ovarian carcinoma } & 2(2.7 \%) \\ \text { Ewing's sarcoma } & 2(2.7 \%) \\ \text { Germ cell tumor } & 1(1 \%) \\ \text { Nephroblastoma } & 1(1 \%)\end{array}$

Mobilization (\%)

Chemotherapy $74(99 \%)$

Cytokine-only $1(1 \%)$

Plerixafor $\quad 12(16 \%)$

GM-CSF $2(3 \%)$

CD34 target yields (\%)

$10-15 \times 10^{6} / \mathrm{kg} \quad 62(83 \%)$

$3 \times 10^{6} / \mathrm{kg}$

$13(17 \%)$

$\begin{array}{ll}\text { Femoral CVC placement (\%) } & \\ \text { Right } & 70(95 \%) \\ \text { Left } & 4(5 \%) \\ \text { Platelet transfusion } & \text { b } \\ \end{array}$

CVC brand ${ }^{\mathrm{c}}(\%)$

medCOMP $26(35 \%)$

Mahurkur $26(35 \%)$

Arrow international $\quad 15(20 \%)$

Unknown $8(10 \%)$

$\begin{array}{ll}\text { No. HPCC procedures/patient (\%) } \\ 1 \\ 2 & 53(71 \%) \\ 3 \text { or more } & 10(13 \%) \\ & 12(16 \%)\end{array}$

${ }^{\mathrm{a}}$ mean $\pm \mathrm{SD}$

${ }^{\mathrm{b}}$ No. patients requiring a platelet transfusion before femoral CVC placement ${ }^{\mathrm{c}}$ Mahurkar, Covidein, Mansfield, MA; medCOMP, Haleysville, PA; Arrow International, Reading, PA.

\subsection{HPC collection and processing}

All patients underwent large volume leukapheresis (LVL, 3 blood volumes) using either the COBE Spectra and WBC collection set or SPECTRA Optia and CMNC software as previously described. ${ }^{15,17}$ Cell counts were performed on the Sysmex XE 5000 (Sysmex, Kobe, Japan). The WBC differential was determined manually. Peripheral CD34 counts and product yields were determined by flow cytometry, as recommended by the International Society of Hematology and Graft Engineering with modification. ${ }^{18,19}$ Cells were volume adjusted and frozen in 10\% dimethyl sulfoxide as previously described. ${ }^{17,18}$ All cell processing was performed in biosafety hoods, located within a certified clean room.

\subsection{Sterility testing and positive cultures}

Sterility testing of each product was performed before and after processing using the USP culture method per $21 \mathrm{CFR}$ $610.12 .{ }^{20}$ All positive cultures were investigated and findings documented in the product record and master excel file. Recorded data included: culture results from the patient and product (pre- and post-processing); identification of the microorganism, date of positive culture; and presence/ absence of infusion reactions.

\section{5 | Data analysis}

Quantitative data were reported as the mean \pm standard deviation (SD) unless noted otherwise. Variables with wide interpatient values were reported as mean, median and range. CD34 and MNC fractional efficiencies (CD34-FE, CD34$\mathrm{FE}$ ) were calculated as described, where $\mathrm{FE}=$ total cell yield/(pre-procedure peripheral cell count) $\times$ (total blood volume processed). ${ }^{21}$ Categorical data were analyzed by $\chi^{2}$ and odds ratio using EpiInfo (Center for Disease Control, Atlanta, GA). Linear regression, $t$ test (paired, unpaired), and graphics were performed with commercial software (Kaliedograph ${ }^{\circledR}$, Synergy Software, Reading, PA). A $P$ values $<0.05$ was considered statistically significant.

\section{3 | RESULTS}

\section{1 | Patient demographics}

A total of 119 pediatric patients underwent A-HPCC between 2009 and January 2017. Eighty-two patients (69\%) underwent leukapheresis using a femoral CVC. Seven patients were excluded due to A-HPCC collection on the SPECTRA Optia and MNC program. In total, 75 patients (63\%) and 119 procedures were eligible for further study. The median patient age was 3 years (range, 10 months to 17 years), with $25 \%$ and $69 \%$ of children $<3$ and $\leq 5$ years of 
TABLE 2 Patients who required three or more A-HPCC procedures

\begin{tabular}{|c|c|c|c|c|c|c|c|c|c|c|c|}
\hline \multirow[b]{2}{*}{$\begin{array}{l}\text { Pt. } \\
\text { No. }\end{array}$} & \multirow[b]{2}{*}{$\begin{array}{l}\text { Age/ } \\
\text { Sex }\end{array}$} & \multirow[b]{2}{*}{ Diagnosis $^{\mathrm{a}}$} & \multicolumn{3}{|c|}{ Mobilization regimen } & \multicolumn{6}{|c|}{ CD34/kg yields per procedure day } \\
\hline & & & $\begin{array}{l}\text { Mobilizing } \\
\text { chemotherapy }^{a}\end{array}$ & $\begin{array}{l}\text { G-CSF } \\
\left(\mu \mathrm{g} \mathrm{kg}^{-1}\right. \\
\left.\text { day }^{-1}\right)^{\mathbf{b}}\end{array}$ & $\begin{array}{l}\text { Plerixafor } \\
\left(^{(D a y)^{c}}\right.\end{array}$ & $\mathbf{1}$ & 2 & 3 & 4 & 5 & 6 \\
\hline 7 & $5 / \mathrm{F}$ & Hepatoblastoma & ICE & $10->17$ & $1-2$ & 0.3 & 1.4 & 1.5 & - & - & - \\
\hline 17 & $13 / \mathrm{M}$ & $\begin{array}{l}\text { Pineal Germ } \\
\text { Cell Tumor }\end{array}$ & $\begin{array}{l}\text { Cisplatin } \\
\text { Cyclophosphamide }\end{array}$ & $10->20$ & $1-3^{c}$ & 0.7 & 0.9 & 3.8 & 4.9 & - & - \\
\hline 19 & $12 / \mathrm{M}$ & Medulloblastoma & Cyclophosphamide & $10->14$ & $1-3$ & 0.2 & 1.8 & 1.2 & 1.2 & - & - \\
\hline 21 & $3 / \mathrm{M}$ & Lymphoma (NHL) & Cyclophosphamide & 10 & 3 & 0.5 & 0.4 & 0.8 & 1.4 & - & - \\
\hline 25 & $5 / \mathrm{M}$ & Neuroblastoma & ICE & $10->18$ & $1-2$ & 0.5 & 0.5 & 0.9 & - & - & - \\
\hline 32 & $15 / \mathrm{F}$ & Lymphoma (NHL) & R-ICE & 10 & $4-6^{\mathrm{d}}$ & 0.2 & - & - & 0.8 & 0.9 & 0.9 \\
\hline 43 & $9 / \mathrm{F}$ & Ovarian Cancer & $\begin{array}{l}\text { ABVE } \\
\text { Cisplatin } \\
\text { Cyclophosphamide }\end{array}$ & $10->20$ & none & 0.9 & 1.1 & 2.6 & - & - & - \\
\hline 45 & $4 / \mathrm{F}$ & PNET & ACNS 0333 & $\begin{array}{l}10->16 \\
+ \text { GM-CSF }\end{array}$ & $2-5$ & 0.2 & 0.2 & 0.5 & 1.3 & 4.1 & 3.7 \\
\hline 48 & $2 / \mathrm{F}$ & Neuroblastoma & IE & $10->20$ & $1-2$ & 0.6 & 2.5 & 4 & - & - & - \\
\hline 49 & $11 / \mathrm{M}$ & Medulloblastoma & $\begin{array}{l}\text { Cisplatin } \\
\text { Lomustine } \\
\text { Vincristine }\end{array}$ & 10 & $1-2$ & 1.7 & 2.2 & 3.8 & - & - & - \\
\hline 50 & $10 / \mathrm{F}$ & $\begin{array}{l}\text { Ovarian mixed } \\
\text { germ cell tumor }\end{array}$ & Cyclophosphamide & 10 & $2-4^{\mathrm{c}}$ & 0.3 & 0.7 & 0.4 & 1.7 & 1.3 & - \\
\hline 55 & $13 / \mathrm{M}$ & Lymphoma (HL) & ICE & $\begin{array}{l}10, \\
+\mathrm{GM}-\mathrm{CSF}\end{array}$ & $2-4^{\mathrm{c}}$ & 0.2 & 0.5 & 1.7 & 1.9 & - & - \\
\hline
\end{tabular}

aAbbreviations: -, not performed. ABVE, adriamycin, bleomycin, vincristine, etoposide; ACNS 0333; cisplatin, etoposide, cyclophosphamide, vincristine, methotrexate; IE/ICE/R-ICE, ifosphamide, carboplatinum, etoposide \pm rituximab (R); NHL, non-Hodgkin's lymphoma; PNET, primitive neuroectodermal tumor;.

${ }^{\mathrm{b}}$ Daily G-CSF dose at time of first A-HPCC. Several patients had an increase in dose (->) during course of A-HPCC.

${ }^{\mathrm{c}}$ Day plerixafor administered for A-HPCC the next day. In general, plerixafor was administered in the early evening ( $\sim 8$ pm), $\sim 12 \mathrm{~h}$ prior to scheduled leukapheresis as recommended in the package insert. In two patients (17 and 50), the first dose of plerixafor administration was inadvertently administered after midnight. In Patient 55, plerixafor was actually given the morning of Day2, an hour prior to leukapheresis. The first effective dose, therefore, is Day 3.

${ }^{\mathrm{d}}$ Patient 32 did not undergo A-HPCC on days 2 and 3 due to low CD34+ counts and evidence of persistent delayed marrow recovery.

age, respectively (Table 1). Most children (74/75) were collected following mobilizing chemotherapy. The majority of patients (84\%) required only $1-2$ procedures.

Twelve patients required three to six procedures to collect sufficient cells for transplant (Table 2). Patients requiring three or more procedures were generally older (median age, 9.5 years),

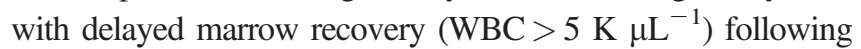
cancer-specific chemotherapy (18.1 \pm 1.5 days versus 13 days, cyclophosphamide, $P=0.06$ ). Several patients required an increase in G-CSF dosing $(7 / 12,58 \%)$, often supplemented with $\operatorname{GM}-\operatorname{CSF}(2 / 12,17 \%)$ and/or plerixafor $(11 / 12,92 \%)$.

\section{2 | Laboratory studies}

The mean peripheral WBC on Day 1 was $23 \pm 17 \mathrm{~K}_{\mu} \mathrm{L}^{-1}$

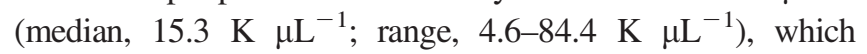

continued to slowly increase over time (Table 3; Figure 1S, Supporting Information). The mean absolute MNC count on

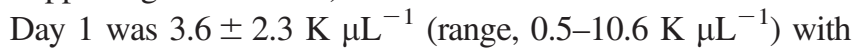
the highest counts on Day 3. The mean peripheral CD34 counts were highest on Day $1(333 \pm 49 / \mu \mathrm{L}$ SEM; median, 199; range, $1-1,740 / \mu \mathrm{L}: P<0.0001)$ due to a large cohort of well-mobilized young children. As a result, $71 \%$ of patients collected in a single procedure. Patients who required two or more procedures had significantly lower peripheral CD34 counts on subsequent days (Table 3). The mean pre-procedure

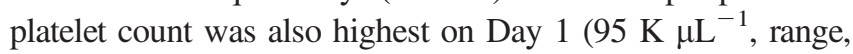
$\left.35-253 \mathrm{~K}^{2} \mathrm{~L}^{-1} ; P=0.003\right)$ but fell $24-29 \%$ due to procedure-related platelet losses (Table 3, Supporting Information Figure S1). Six patients required a total of 10 additional platelet transfusions during the course of A-HPCC (Days 3-5) for procedure-related platelet losses (Table 3). 
TABLE 3 A-HPC collection by day

\begin{tabular}{|c|c|c|c|c|c|}
\hline & \multirow[b]{2}{*}{ All procedures } & \multicolumn{4}{|l|}{ Procedure day } \\
\hline & & Day 1 & Day 2 & Day 3 & Days 4-6 \\
\hline \multicolumn{6}{|l|}{ A-HPCC } \\
\hline No. procedures & 119 & 75 & 22 & 12 & 10 \\
\hline No. patients & 75 & 75 & 22 & 12 & 7 \\
\hline Median age (years) & 3 & 3 & 6 & 8.5 & 12 \\
\hline Median weight (kg) & 16.4 & 16.4 & 20.8 & 29.5 & 42 \\
\hline $\begin{array}{l}\text { Total blood volume (mLa) } \\
\text { (median, range) }\end{array}$ & $\begin{array}{l}1,793 \pm 1,062 \\
(1286,530-4984)\end{array}$ & $\begin{array}{l}1,566 \pm 1,025 \\
(1,611)\end{array}$ & $\begin{array}{l}1,909 \pm 966 \\
(1,909)\end{array}$ & $\begin{array}{l}2,372 \pm 1,029 \\
(2,738)\end{array}$ & $\begin{array}{l}1,793 \pm 1,062 \\
(2,545)\end{array}$ \\
\hline $\begin{array}{l}\text { Liters processed } \\
\quad \text { (median, range) }\end{array}$ & $\begin{array}{l}4.3 \pm 3.5 \\
(3.8,1.2-22.5)\end{array}$ & $\begin{array}{l}4.6 \pm 3.4 \\
(3.5)\end{array}$ & $\begin{array}{l}5.6 \pm 2.9 \\
(4.1)\end{array}$ & $\begin{array}{l}7.2 \pm 3.8 \\
(7.2)\end{array}$ & $\begin{array}{l}7.7 \pm 3.9 \\
(8.7)\end{array}$ \\
\hline Median BV processed & 3 & 3 & 3 & 3 & 3 \\
\hline Total inlet rate $\left(\mathrm{mL} \mathrm{min}^{-1}\right)^{\mathrm{a}}$ & $27.7 \pm 18.3$ & $23 \pm 14.7$ & $32 \pm 19.8$ & $41.1 \pm 26.6$ & $35.6 \pm 16.2$ \\
\hline $\begin{array}{l}\text { Adjusted inlet rate } \\
\qquad\left(\mathrm{mL} \mathrm{kg}^{-1} \min ^{-1}\right)\end{array}$ & $1.1 \pm 0.43$ & $1.09 \pm 0.37$ & $1.14 \pm 0.42$ & $1.3 \pm 0.79$ & $0.98 \pm 0.14$ \\
\hline \multicolumn{6}{|l|}{ Pre-peripheral blood counts } \\
\hline $\operatorname{WBC}\left(10^{9} / \mathrm{L}\right)^{\mathrm{a}}$ & $24.7 \pm 16.8$ & $22.7 \pm 17.3$ & $24 \pm 14.3$ & $33.1 \pm 17.6$ & $31.3 \pm 13.2$ \\
\hline$\% \mathrm{MNC}^{\mathrm{a}}$ & $7.5 \pm 10.6$ & $18.9 \pm 11.6$ & $16 \pm 8.2$ & $15.8 \pm 8.9$ & $12.9 \pm 7.7$ \\
\hline $\operatorname{MNC}\left(10^{9} / \mathrm{L}\right)^{\mathrm{a}}$ & $3.6 \pm 2.3$ & $3.3 \pm 2.7$ & $3.5 \pm 2.7$ & $4.5 \pm 2.7$ & $3.4 \pm 1.6$ \\
\hline $\mathrm{CD} 34(\text { per } \mu \mathrm{L})^{\mathrm{b}}$ & $224.3 \pm 34.4$ & $333.1 \pm 48.9^{c}$ & $32.1 \pm 8.5$ & $13.1 \pm 7.1$ & $23.5 \pm 7.2$ \\
\hline Platelet $\left(10^{11} / \mathrm{L}\right)^{\mathrm{a}}$ & & $96.9 \pm 44.3^{\mathrm{d}}$ & $73 \pm 32.3$ & $75.3 \pm 35.4$ & $69.1 \pm 30.6$ \\
\hline \multicolumn{6}{|l|}{ Cell Yields } \\
\hline $\mathrm{CD} 34 / \mathrm{kg}\left(\times 10^{6}\right)^{\mathrm{a}}$ & $23.5 \pm 35.8$ & $35.6 \pm 40.5^{\mathrm{c}}$ & $4 \pm 4.5$ & $1.8 \pm 1.3$ & $2.2 \pm 1.4$ \\
\hline $\mathrm{MNC} / \mathrm{kg}\left(\times 10^{8}\right)^{\mathrm{a}}$ & $3.3 \pm 2.2$ & $3.1 \pm 2.3$ & $3.3 \pm 2.3$ & $4.5 \pm 2.3$ & $3.5 \pm 1.9$ \\
\hline Platelet transfusions & 78 & 52 & 10 & 7 & 9 \\
\hline Preprocedure & $50^{\mathrm{e}}$ & $40^{\mathrm{e}}$ & 4 & 3 & 3 \\
\hline CVC removal & 28 & 12 & 6 & 4 & 6 \\
\hline
\end{tabular}

${ }^{\mathrm{a}}$ Results are mean $\pm \mathrm{SD}$.

${ }^{\mathrm{b}}$ Results are mean \pm SEM.

${ }^{\mathrm{c}}$ Peripheral CD34/ $\mu \mathrm{L}$ and CD34/kg significantly higher on Day $1(P<0.0001)$.

${ }^{\mathrm{d}}$ Peripheral platelet count significantly higher on Day $1(P=0.003)$.

${ }^{\mathrm{e}}$ Forty patients received a platelet transfusion prior to femoral CVC insertion (see Table 1).

\section{3 $\mid$ Femoral line characteristics}

All patients had a femoral line placed under anesthesia without complication. Fifty-three percent of patients required a platelet transfusion prior to CVC placement (Table 1). Most children had CVC placed in the right femoral vein (95\%): Four children had left-sided femoral CVC due to anatomic issues and tumor involvement. Details regarding the CVC size and manufacturer were available in $67(89 \%)$ patients (Table 1).

The median CVC size for all patients was 10 French (range, 7-14). In young children ( $<5$ years), the median catheter size was 10 French (range, 7-12) including 50\% of children under 3 years of age (Figure 1A). In children older than 5 years, the vast majority required a 12 French $\mathrm{CVC}$ or larger. When examined by patient weight (Figure 1B), the median CVC size was as follows: $<10 \mathrm{~kg}$ (8 French; range, $7-8), 10-20 \mathrm{~kg}$ (10 French; range, 7-12) and $>20 \mathrm{~kg}$ (12 French, range, 7-14).

\subsection{Femoral line performance}

Femoral CVC performance over the course of A-HPCC was also examined. CVC performance was analyzed relative to average inlet rates, cell collection rates, cell collection efficiency, and access-related AE.

\subsection{1 | Inlet rate}

The average inlet rate was $27.7 \pm 18.3 \mathrm{~mL} \mathrm{~min}^{-1}$. When corrected for body weight, the mean inlet rate per procedure was $1.1 \pm 0.43 \mathrm{~mL} \mathrm{~min}{ }^{-1} \mathrm{~kg}^{-1}$. Only $20 \%$ of procedures were performed at an inlet rate $<0.9 \mathrm{~mL} \mathrm{~min}^{-1} \mathrm{~kg}^{-1}$ (Figure 2A; range, 0.7-0.89). The highest mean inlet rate was Day 3 $\left(1.3 \pm 0.79 \mathrm{~mL} \mathrm{~min}^{-1} \mathrm{~kg}^{-1}, P=0.37\right)$, but then progressively decreased over the next 3 days (Figure 2B). There was no correlation between inlet rates and either the peripheral WBC count or platelet counts (data not shown). 

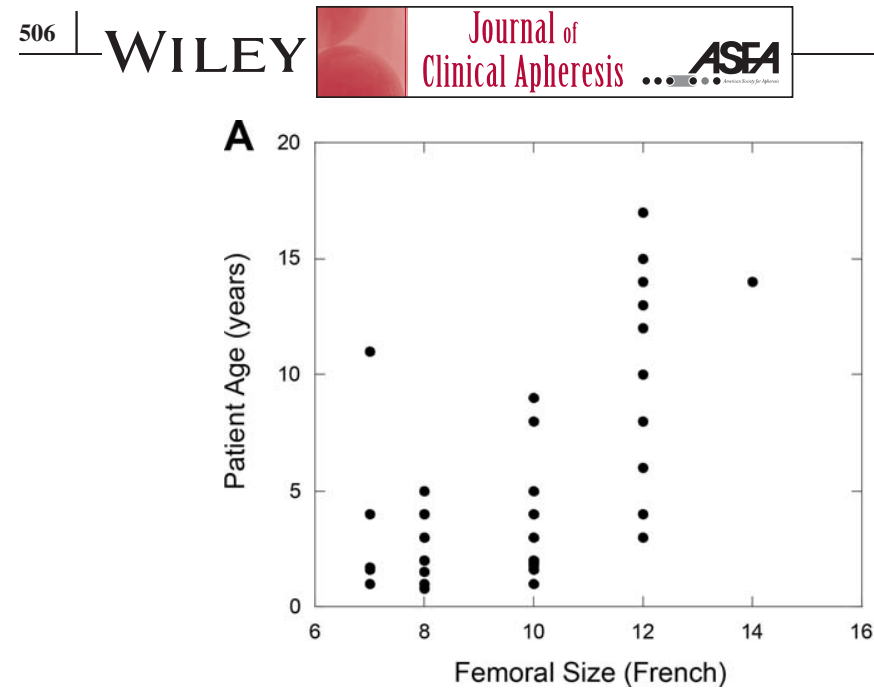

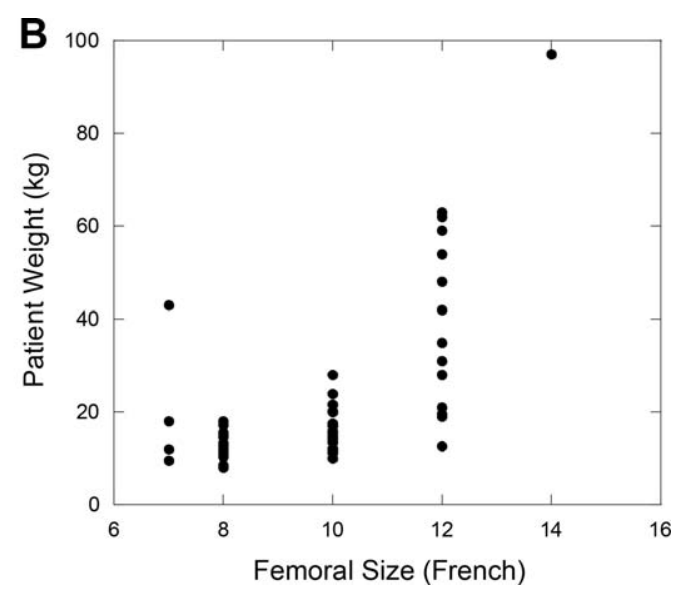

F IG URE 1 Distribution of femoral CVC size by patient age (A) and weight (B)

\subsection{2 | CD34 collection and cell yields}

CD34/kg yields were greatest on Day 1 due to a large cohort of well-mobilized young children (mean, 35.6 $\pm 40 \times$ $10^{6} / \mathrm{kg} ; P<0.0001$ : Table 3). As expected, there was a linear correlation between the peripheral CD34 count and the $\mathrm{CD} 34 / \mathrm{kg}$ yield (Figure 2C, insert; $\mathrm{R}=0.90$ ). We also examined the CD34 collection rate on Day 1 to subsequent procedures (Days 2-6). As shown in Figure 2C, there was no falloff in CD34 collection with subsequent days.

A CD34-FE was available in 111/119 (93\%) procedures. The mean CD34-FE for all collections was $0.59 \pm 0.30$ and was relatively stable over the course of A-HPCC (Figure 2D; range, $0.54-0.59 ; P=0.42-0.90)$. There was also no difference in CD34-FE in patients with left-sided femoral CVC $(0.50 \pm 0.19$ versus $0.59 \pm 0.32$, right; $P=0.37)$. There was no significant correlation between CD34-FE and peripheral WBC count or platelet count (data not shown).

\subsection{3 | MNC collection and cell yields}

The mean MNC was $3.3 \pm 2.2 \times 10^{8} / \mathrm{kg}$ with the highest yield on Day $3(4.5 \pm 1.9, P=0.07$; Table 3$)$. There was a weak linear correlation between $\mathrm{MNC} / \mathrm{kg}$ and peripheral MNC count $(y=1.3+0.56 x, R=0.58)$. There was no difference in the slope or rate of MNC collection rate between Day 1 and subsequent days (Figure 2E).

The mean MNC-FE for all collections was $0.55 \pm 0.44$ (range, 0.11-1.8) and inversely related to absolute MNC count $\left(y=0.86-0.66 \log x, R=-0.47\right.$; data not shown). ${ }^{22}$ Although the median MNC-FE was relatively stable over time (Figure 2F), there was a trend toward improved MNCFE on Day $2(0.72 \pm 0.16, P=0.12)$, with $50 \%$ of all patients showing an increase in MNC-FE (Figure S2, Supporting Information). By Day 4, MNC-FE (0.40 \pm 0.24 , $P=0.37$ ) fell by $10-73 \%$ in $80 \%$ of patients (Supporting Information Figure S2) and mirrored the drop in inlet rate.

\subsubsection{Line-associated adverse events during A-HPCC}

Ten bleeding and/or flow-related $\mathrm{AE}$ were documented in eight patients for an overall rate of $8 \%$ per procedure and $11 \%$ per patient (Table 4 ). Two patients had mild oozing on Day 1 that was easily controlled by a pressure dressing. In a third patient, there was significant oozing on Day 3 that was unresponsive to pressure and required application of a topical clotting agent and platelet transfusion (pre-procedure platelet

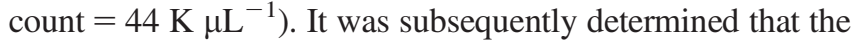
line had dislodged a short distance.

Five patients had alarms and flow-related issues over the course of A-HPCC. Three patients required either repeated line flushing $(n=2)$ or line reversal $(n=2)$ on Day 2. While both patients who required line reversal experienced a decrease in CD34-FE $(22 \%, 60 \%)$ relative to Day 1, there was no clinical evidence of recirculation per nursing notes. One patient developed new and significant difficulties in establishing an interface on Day 4 that prolonged the procedure by 30-40 min. Another patient experienced a 30\% decrease in flow rate $\left(0.7 \mathrm{~mL} \mathrm{~min}^{-1} \mathrm{~kg}^{-1}\right)$ on Day 6 .

\subsection{Comparison of femoral and thoracic CVC in pediatric A-HPCC}

We also compared the performance of femoral CVC to a small cohort of 19 pediatric patients who underwent AHPCC using thoracic CVC $(n=9$ internal jugular, $n=10$ subclavian; 33 procedures) during the same time interval. Patients with thoracic CVC were significantly older (13 \pm 6.6 years, range, $1-21$ years; $P<0.0001)$ and heavier $(58 \pm$ $32 \mathrm{~kg}$; range, $10-122 \mathrm{~kg} ; P=0.0002)$ than patients with femoral CVC. The most common diagnosis in these patients was lymphoma (47\%), followed by brain cancer (21\%), neuroblastoma (16\%), testicular carcinoma (11\%), and Ewing's sarcoma (5\%). Because some patients had CVC placed at 

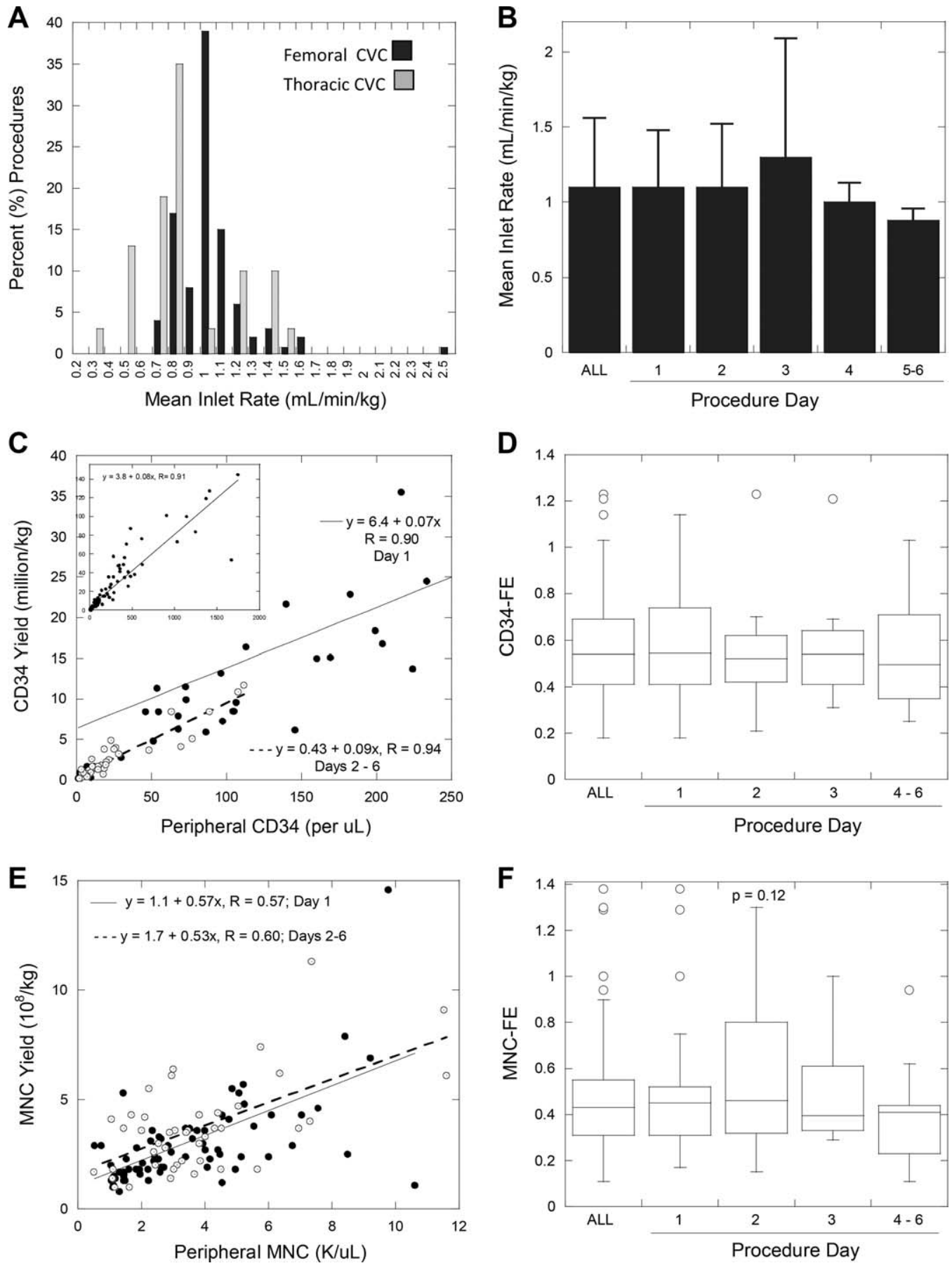

F IG URE 2 Femoral CVC performance. (A) Distribution of inlet rate/minute/kg by patient weight in pediatric patients with femoral CVC (black) and thoracic CVC (gray). (B) Mean inlet rate by day. (C) CD34 collection rate (CD34 yield per peripheral CD34 count) comparing Day 1 ( $~-—$ ) versus subsequent days (Day 2-6, - - - -). Insert, CD34 collection rate for all procedures. (D) CD34-FE for all patients by procedure day. (E) MNC collection rate comparing Day $1(-)$ versus Days 2-6 (-o-). (F) MNC-FE for all patients by procedure day. The number of procedures per day is listed in Table 3. Data in figures $\mathrm{D}$ and $\mathrm{F}$ are box plots, showing the median, 25th and 75th percentile, bracketed lines are the minimum and maximum values based on the interquartile range (IQR). Values exceeding $3 \mathrm{IQR}$ are outliers and are denoted by open circles

outside facilities, the catheter size was only available in $81 \%$ of patients. The median thoracic CVC size was 12 French (range, 6-14). In children under $20 \mathrm{~kg}$, a 6 to 7 French CVC was placed $(n=3)$.

In terms of catheter performance, the total mean inlet rate with thoracic $\mathrm{CVC}$ was $44 \pm 20 \mathrm{~mL} \mathrm{~min}{ }^{-1}$. When corrected for body weight, however, thoracic CVC had a slower inlet rate than femoral CVC $\left(0.92 \pm 0.31 \mathrm{~mL} \mathrm{~min}^{-1}, P=0.02\right.$ : Figure $2 \mathrm{~A})$. The mean CD34-FE $(0.51 \pm 0.20$ versus 0.59 femoral, $P=0.18)$ and MNC-FE $(0.48 \pm 0.28$ versus 0.55 femoral) was $13-15 \%$ lower than femoral CVC, although the difference was not statistically significant $(P=0.18-0.41)$. 
TABLE 4 Incidence of CVC-associated AE during A-HPCC

\begin{tabular}{|c|c|c|c|c|c|c|c|}
\hline & \multirow{2}{*}{$\begin{array}{l}\text { Femoral CVC } \\
(n=75)\end{array}$} & \multicolumn{6}{|l|}{ Thoracic CVC ${ }^{a}$} \\
\hline & & Total $^{\mathrm{a}}(n=38)$ & $P^{\mathbf{b}}$ & Pediatric $^{\mathrm{c}}(n=19)$ & $P^{\mathbf{b}}$ & Adults $^{\mathrm{d}}(n=19)$ & $P^{\mathbf{b}}$ \\
\hline No. patients access AE (\%) & $8(10.7 \%)$ & $12(31.6 \%)$ & 0.006 & $8(42 \%)$ & 0.0011 & $4(21 \%)$ & 0.23 \\
\hline Bleeding & $3(4 \%)$ & $2(5.3 \%)$ & 0.76 & $1(5.3 \%)$ & 0.80 & $1(2.6 \%)$ & 0.80 \\
\hline Flow-related $\mathrm{AE}^{\mathrm{e}}$ & $5(6.7 \%)$ & $10(26.3 \%)$ & 0.004 & $7(37 \%)$ & 0.0005 & $3(15.8 \%)$ & 0.20 \\
\hline Repeated flushing & $2(2.7 \%)$ & $3(7.9 \%)$ & & $2(10.5 \%)$ & & $1(5.3 \%)$ & \\
\hline Line reversal & $2(2.7 \%)$ & $1(2.6 \%)$ & & 0 & & $1(5.3 \%)$ & \\
\hline Slow inlet rate & $2(2.7 \%)$ & $9(23 \%)$ & & $6(31.6 \%)$ & & $3(15.8 \%)$ & \\
\hline Interface issues & $1(1.3 \%)$ & $1(2.6 \%)$ & & $1(5.3 \%)$ & & 0 & \\
\hline Alternate IV access & 0 & $4(10.5 \%)$ & & $2(10.5 \%)$ & & $2(10.5 \%)$ & \\
\hline Recirculation & 0 & $1(2.6 \%)$ & & 0 & & $1(2.6 \%)$ & \\
\hline Aborted procedure & 0 & $3(7.9 \%)$ & & $2(10.5 \%)$ & & $1(2.6 \%)$ & \\
\hline
\end{tabular}

adult and pediatric patients with thoracic CVC.

${ }^{\mathrm{b}}$ Significance relative to pediatric femoral CVC patients by $\chi^{2}$.

${ }^{\mathrm{c} P e d i a t r i c}$ other CVC: 10 subclavian, 9 internal jugular.

${ }^{\mathrm{d}}$ Adult myeloma patients collected with thoracic (subclavian) CVC between 2010 and 2013.

${ }^{\mathrm{e}}$ More than one flow-related AE in some patients over the course of A-HPCC.

Among 7/19 patients who underwent multiple A-HPCC with thoracic CVC, there was a drop in both CD34-FE (0.38 vs. 0.55 Day $1 ; P=0.18$, paired t-test) and MNC-FE (0.43 vs. 0.52 Day $1, P=0.37$ ) by the second or third procedure.

A comparison of access-related $\mathrm{AE}$ by $\mathrm{CVC}$ type indicated a substantially lower incidence $(6.7 \%$ vs. $37 \%, P=$ 0.0005) and risk for flow-related $\mathrm{AE}$ with femoral CVC $(\mathrm{OR}=0.12 ; 95 \% \mathrm{CI}, 0.03-0.45)$ (Table 4$)$. We also compared the incidence of CVC-AE in pediatric patients to an equivalent cohort of adult multiple myeloma patients (19/81 patients), ${ }^{15}$ who also underwent A-HPCC using thoracic CVC (Table 4). As shown in Table 4, pediatric patients with thoracic CVC also had higher flow-related $\mathrm{AE}$ rates than their adult counterparts (37\% vs. $16 \%, P=0.14$ ). In both pediatric and adult patients, flow related $\mathrm{AE}$ associated with thoracic CVC tended to be more severe than femoral CVC, including placement/use of alternate IV access, recirculation, circuit clotting, and aborted procedures.

\subsection{Catheter performance in individual patients over time}

Although the mean CD34-FE was stable over time, there was significant inter- and intra-patient variability between collections (Figure 2S, Supporting Information). Because there was a trend toward decreasing inlet rate and MNC-FE after Day 3, we performed a detailed analysis of cell collection in 12 patients who required three or more procedures. Nine patients had complete data for all A-HPCC: In three patients, a preprocedure peripheral CD34 count was not performed on one or more days. As shown in Figure 3, CD34-
FE varied over the course of collection and was unique for each patient. All patients successfully collected sufficient cells for transplant (Table 2).

Interestingly, there was an apparent drop in CD34-FE in several patients within 12 to $24 \mathrm{~h}$ after receiving the first dose of plerixafor (patients 7, 17, 21, 32, 45, 48, 49, and 55). Even though all patients showed a progressive increase in WBC over the course of A-HPCC, particularly after receiving plerixafor, there was no clear relationship between WBC

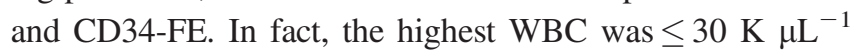
in 6/9 evaluable patients. There was also no correlation between CD34-FE and either the pre-procedure platelet count or recent platelet transfusion (data not shown).

Finally, we compared the course of CD34-FE with MNC-FE in 10 patients (Figure 4A). In general, the MNCFE declined over the course of A-HPCC. Surprisingly, the CD34-FE and MNC-FE showed a similar pattern in patients (Figure 4A). The mean MNC-FE $(0.59 \pm 0.4)$ and CD34-FE $(0.56 \pm 0.24, P=0.55)$ in these patients were nearly identical (Figure 4B). Likewise, there was a linear correlation between the MNC-FE and CD34-FE (Figure 4C, $R=0.68$ ). There was no correlation between CD34-FE, MNC-FE and MNC content (\%MNC) of the product. Three patients showed an alternating pattern between CD34-FE and MNCFE (Figure 3S, Supporting Information), suggesting possible technical issues with cell separation and interface stability.

\section{7 $\quad$ Femoral line removal}

Femoral lines were removed 6-24 $\mathrm{h}$ after the last A-HPCC at the bedside or in the operating room in conjunction with 

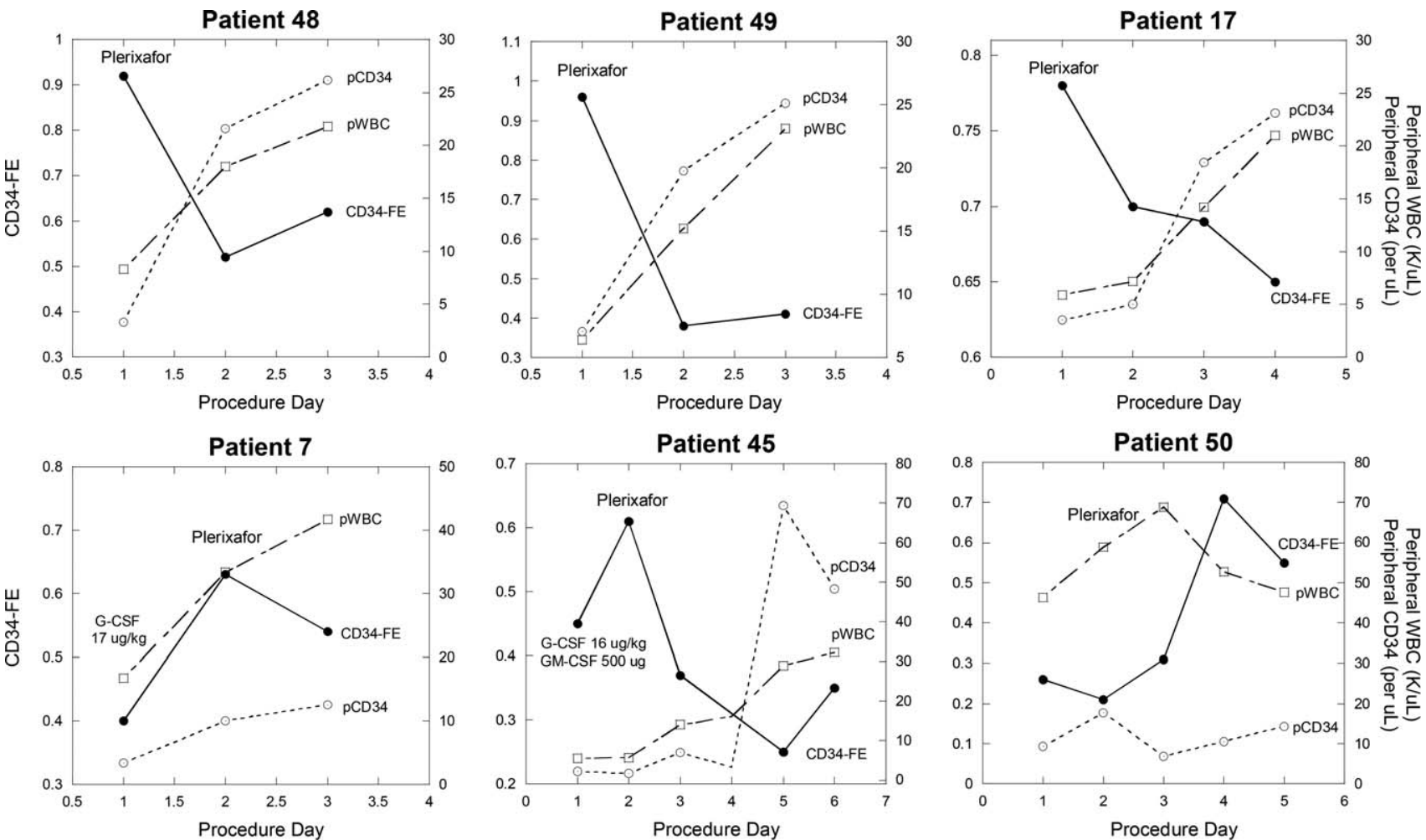

Patient 45

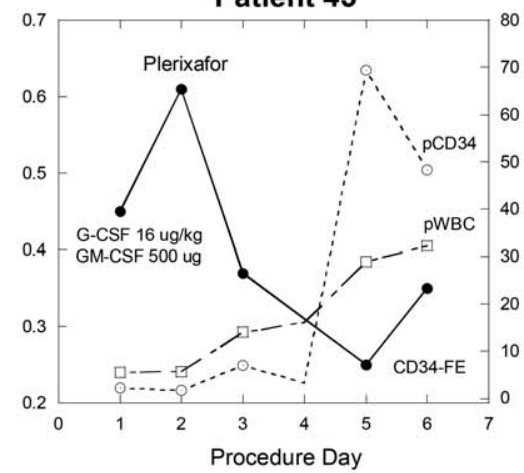

Patient 50

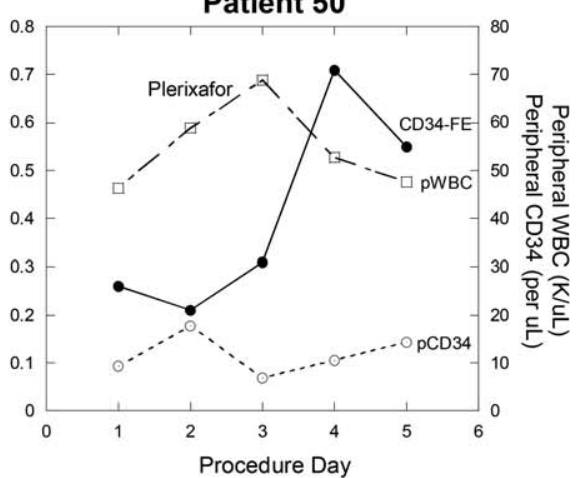

Patient 21
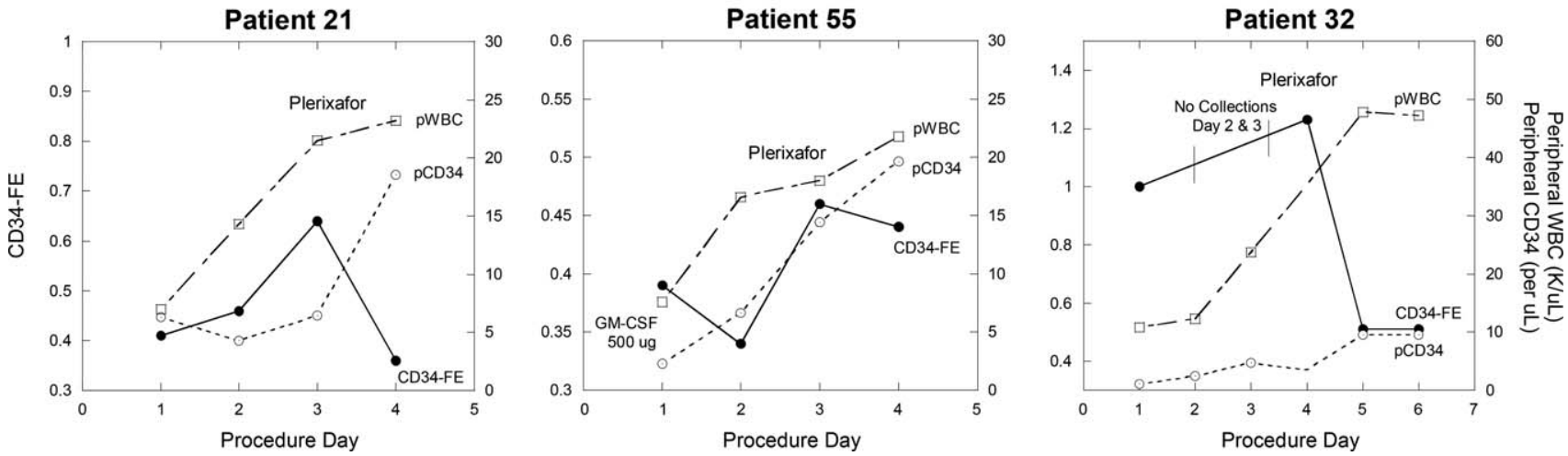

F I G URE 3 Correlation between CD34-FE, peripheral CD34 and WBC counts in nine individual pediatric patients undergoing A-HPCC using a

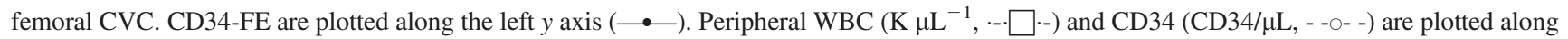
the right $y$ axis. Also shown are changes in G-CSF dosing and the addition of GM-CSF and plerixafor. Please note that in patients 17 and 50, plerixafor had been inadvertently administered in the early morning hours, $<6 \mathrm{~h}$ prior to A-HPCC. In Patient 55, plerixafor had been administered by IV immediately prior to A-HPCC

another procedure. Approximately 37\% (28/75) of patients required a platelet transfusion before $\mathrm{CVC}$ removal due to procedure-related platelet losses. An additional 6 patients had received pre-procedure platelet transfusion on the day of line removal. The mean platelet count prior to CVC removal

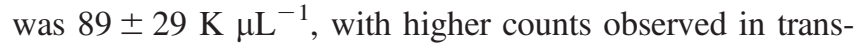

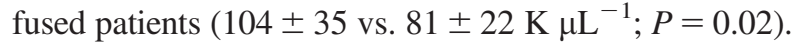

In $72 / 74(97 \%)$ patients, there were no complications associated with femoral CVC removal. Hemostasis was achieved after 5-40 min (median time, $20 \mathrm{~min}$ ) of direct pressure. There was also no clear correlation between the platelet count and time to hemostasis (Figure 4S, Supporting Information). Patients who clotted within $20 \mathrm{~min}$ had platelet counts ranging

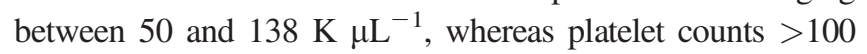

$\mathrm{K} \mu \mathrm{L}^{-1}$ were documented in four patients who required pressure for $30 \mathrm{~min}$ or longer. Platelet transfusion did not shorten the time to hemostasis (median time, $20 \mathrm{~min}$ in transfused and nontransfused). Two patients experienced bleeding following femoral CVC removal. In both patients, there was no evidence of an underlying coagulopathy. The patients had normal liver function and PT values. There was no history of an inheritable clotting disorder. Neither patient was receiving systemic heparin or other anticoagulants.

One Patient (41 kg, 6-year-old female) underwent a single A-HPCC collection with a post-procedure platelet count of $44 \mathrm{~K} \mu \mathrm{L}$. She received a platelet transfusion prior to line removal. Following removal, the CVC site was noted to have prolonged oozing. The patient's hospital stay was 

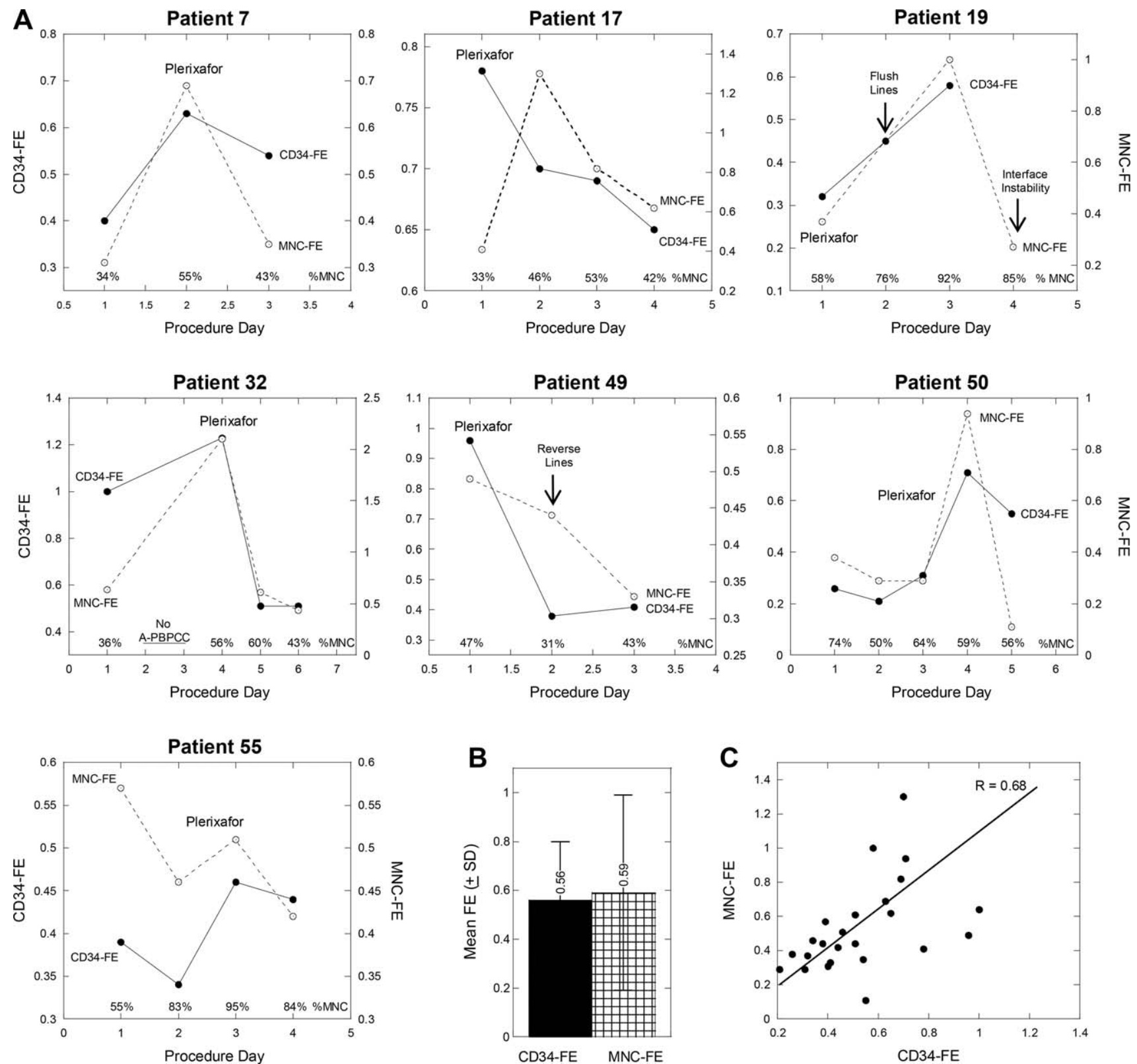

F I G U RE 4 Correlation between CD34-FE and MNC-FE in individual patients. (A) CD34-FE and MNC-FE values are plotted along the left ( $\longrightarrow-$ ) and right (- -- -) $y$-axis, respectively. The MNC content (\%MNC) of the collected product is denoted along the $X$-axis. Line and flow related issues in three patients $(19,49,45)$ are also shown. (B) Mean CD34-FE and MNC-FE for all seven patients. (C) Linear correlation between MNC-FE and CD34-FE.

extended an additional night for observation. She was discharged the following morning with no evidence of bleeding or hematoma.

The second case involved a $12 \mathrm{~kg}$, 3-year old who underwent one A-HPCC, followed by line removal later that evening. The patient initially achieved hemostasis after $15 \mathrm{~min}$ of pressure, but subsequently developed increased bleeding that did not respond to pressure $(80 \mathrm{~min})$ and platelet transfusion. Hemostasis was finally achieved after application of a topical adhesive by Pediatric Surgery. A small hematoma was noted the following morning. Post-procedure $(4 \mathrm{~h})$ laboratory studies showed an adequate platelet count (84 $\left.\mathrm{K} \mu \mathrm{L}^{-1}\right)$, but a prolonged aPTT (119 seconds (s); normal range, 22-32 s). A repeat aPTT was improved, but still elevated $(38.2 \mathrm{~s})$. Of note, this patient had a long-term, tunneled $\mathrm{CVC}$ for infusions and blood draws with multiple prolonged aPTT, consistent with heparin-contamination. ${ }^{23}$

There were no reports of infection, thrombosis, limb swelling, extravascular effusions, or arteriovenous fistulas associated with femoral CVC in any patient in this series. ${ }^{9,10,13}$

\subsection{Product sterility}

There were no positive cultures in any product collected ( $0 /$ $118)$. In a 10-year retrospective review of all pediatric AHPCC, only 4/338 (1.1\%) products from 3/197 patients 
(1.5\%) were culture positive. Two products were collected via femoral $\mathrm{CVC}$ for an estimated culture-positive rate of $0.7 \%$ per product and $1.2 \%$ per patient. In both cases, only the post-processing sample was positive with a nonviable organism after 11-14 days of culture, consistent with a lab contaminant.

Two products from the same patient were culture positive with coagulase-negative Staphylococcus within 5-7 days. The patient, catheter tip, and products (pre- and post-processing) were positive with coagulase-negative Staphylococcus. This was considered a true positive attributed to a colonized subclavian CVC $\left(\right.$ PowerLine $^{\circledR}$ ) placed $\sim 1$ month earlier. ${ }^{7}$

\section{4 | DISCUSSION}

In this study, we describe our single-institution experience using femoral CVC for stem cell collection in children, including children as young as 10 months. Children typically undergo femoral line placement in the morning of their first scheduled A-HPCC. The vast majority (84\%) of the children in this series collected in one or two procedures with only $16 \%$ patients requiring a line for 3 or more days. CVC were subsequently removed by BMT staff within 6-24 h after the last A-HPCC. Hemostasis was achieved after 10-30 min of pressure without complication in $97 \%$ patients. Only two patients experienced prolonged bleeding, with one patient developing a small hematoma. There were no patients who experienced serious long-term sequlae following femoral CVC placement.

Clinically, there were few issues with femoral CVC for A-HPCC. A total of 10 AE were documented in $10.7 \%$ patients and $8.4 \%$ procedures. AE were limited to mild bleeding and flow-related AE, which were amendable to correction by routine maneuvers. This was significantly better than the $\mathrm{AE}$ rate in 19 pediatric patients with thoracic $\mathrm{CVC}$ (42\%, $P=0.001$ ). Pediatric patients with thoracic CVCs had a significantly higher rate of flow-related AE and were more likely to have prolonged procedures due to a slow inlet rate $\left(<0.7 \mathrm{~mL} \mathrm{~min}{ }^{-1} \mathrm{~kg}^{-1}\right)$, require alternate venous access, and in two patients, early termination of the procedure (Table 4). ${ }^{15}$ Finally, there were no confirmed cases of bacterial contamination using femoral CVC in the last 10-years whereas a tunneled thoracic CVC was linked to lineassociated bacterial contamination of two products.

These results are equivalent or better than those reported in adults (Table 5). ${ }^{1,4,24-41}$ Shariatmadar and Noto reported bleeding in 1/63 (1.6\%) of autologous adult patients, with no episodes of occlusion or flow-related AE, even after 6 days. $^{24}$ In contrast, Moreiras-Plaza et al. encountered catheter-related flow issues in 12\% (29/232) of procedures that were resolved by patient repositioning or reversing lines: other AE included minor bleeding after insertion (2\%) and hematoma $(15.8 \%){ }^{25}$ A larger study of 147 adults and 488 $\mathrm{HPCC}$ reported catheter-related AE rate in $5 \%$ of procedures and $16.8 \%$ of patients. Documented AE included bleeding and large hematomas requiring platelet transfusion or red cell transfusion $(6.8 \%)$; catheter malplacement, occlusion and thrombosis $(8.1 \%)$; arteriovenous fistulas (1.3\%); and infection $(0.6 \%){ }^{26}$ Breast cancer patients were particularly susceptible to thrombosis, with femoral vein thrombosis and pulmonary embolism in $4.7 \%$ and $5.9 \%$ of patients, respectively. ${ }^{27}$ More recently, Donmez observed a $1.8 \%$ occlusion rate and $10.7 \%$ overall $\mathrm{AE}$ rate in 268 adults undergoing AHPCC, with bleeding and hematoma accounting for most recorded $\mathrm{AE}(57 \%) .{ }^{28}$ In healthy donors, femoral CVC had a $8.7 \%$ AE rate due to catheter malfunction/malposition (3.5\%) and hematomas $(5.2 \%) .{ }^{29}$ Product contamination rates using femoral CVC in adults are approximately $1 \% .^{28}$

Although femoral CVC access is used by many centers for pediatric $\mathrm{HPCC},{ }^{30,31,42,43}$ there is limited published data regarding catheter performance. Yocco et al. anecdotally reported a high incidence of alarms, obstructions and kinked lines using femoral CVC in children $<3$ years of age,

TABLE 5 Literature review of CVC performance in pediatric and adult HPC collection

\begin{tabular}{|c|c|c|c|c|c|c|c|}
\hline \multirow[b]{2}{*}{ Reference } & \multirow{2}{*}{$\begin{array}{l}\text { CVC } \\
\text { location }\end{array}$} & \multirow{2}{*}{$\begin{array}{l}\text { Patient } \\
\text { type }\end{array}$} & \multirow{2}{*}{$\begin{array}{l}\text { No. } \\
\text { patient }\end{array}$} & \multirow{2}{*}{$\begin{array}{l}\text { No. } \\
\text { HPCC }^{\text {a }}\end{array}$} & \multicolumn{3}{|c|}{ CVC-related AE (\% patients [\% procedures] $)^{\mathbf{b}}$} \\
\hline & & & & & Flow ${ }^{b}$ & Bleeding $^{\mathbf{b}}$ & Other $\mathbf{A} \mathbf{E}^{\mathbf{b}}$ \\
\hline This study & Femoral & Pediatric & 75 & $1(1-6)$ & $6 \%[5.3 \%]$ & $4 \%[2.5 \%]$ & $\begin{array}{l}1.3 \% \text { hematoma } \\
2.6 \% \text { bleeding post-removal }\end{array}$ \\
\hline Sevilla ${ }^{30}$ & Femoral & Pediatric & 12 & $1(1-2)$ & 0 & 0 & $\begin{array}{l}8.3 \% \text { hematoma } \\
25 \% \text { minor bleeding post-removal }\end{array}$ \\
\hline Bolan $^{31}$ & Femoral & Pediatric & 31 & 1 & na & $3.2 \%$ & $3.2 \%$ hematoma \\
\hline Shariamatmadar ${ }^{24}$ & Femoral & Adult & 63 & $1(1-4)$ & 0 & $1.6 \%[1.1 \%]$ & none \\
\hline Sohn $^{29}$ & Femoral & Adult & 57 & $1(1-3)$ & $3.5 \%[1.8 \%]$ & 0 & $5.2 \%$ hematoma \\
\hline
\end{tabular}


TABLE 5 (Continued)

\begin{tabular}{|c|c|c|c|c|c|c|c|}
\hline \multirow[b]{2}{*}{ Reference } & \multirow{2}{*}{$\begin{array}{l}\text { CVC } \\
\text { location }\end{array}$} & \multirow{2}{*}{$\begin{array}{l}\text { Patient } \\
\text { type }\end{array}$} & \multirow{2}{*}{$\begin{array}{l}\text { No. } \\
\text { patient }\end{array}$} & \multirow{2}{*}{$\begin{array}{l}\text { No. } \\
\text { HPCC }^{\text {a }}\end{array}$} & \multicolumn{3}{|c|}{ CVC-related AE (\% patients [\% procedures]) ${ }^{\mathbf{b}}$} \\
\hline & & & & & Flow & Bleeding $^{\mathbf{b}}$ & Other $\mathbf{A E} \mathbf{E}^{\mathbf{b}}$ \\
\hline Adorno $^{26}$ & Femoral & Adult & 147 & $3(1-8)$ & $8.1 \%[2.4 \%]$ & na & $\begin{array}{l}6.8 \% \text { hematoma } \\
4.7 \% \text { thrombosis } \\
0.6 \% \text { infection } \\
1.3 \% \text { arteriovenous fistula }\end{array}$ \\
\hline Moreiras-Plaza $^{25}$ & Femoral & Adult & 95 & $2(1-4)$ & $30.5 \%[12 \%]$ & $2 \%[0.9 \%]$ & $15.8 \%$ hematoma \\
\hline Donmez $^{28}$ & Femoral & Adult & 268 & $3(1-8)$ & $1.8 \%$ & $0.7 \%[0.2 \%]$ & $\begin{array}{l}4.7 \% \text { hematoma } \\
0.7 \% \text { bleeding post-removal } \\
1.8 \% \text { thrombosis } \\
1 \% \text { product contamination }\end{array}$ \\
\hline Saif $^{27}$ & Femoral & Adult & 85 & $2(1-4)$ & 0 & na & $10.6 \%$ thrombosis post-removal \\
\hline Madero $^{32}$ & Thoracic & Pediatric & 56 & $1(1-3)$ & $15 \%$ & na & $\begin{array}{l}7 \% \text { insertion } \mathrm{AE} \\
2.3 \% \text { pneumothorax }\end{array}$ \\
\hline Fishmeister $^{4}$ & Thoracic & Pediatric & 46 & $3(1-10)$ & $28 \%[20 \%]$ & 0 & $0.6 \%$ infection \\
\hline Orbach $^{33}$ & Thoracic & Pediatric & 24 & $2(1-4)$ & $16 \%$ & 0 & \\
\hline Gorlin $^{1}$ & Thoracic & Pediatric & 14 & $6(3-8)$ & $64 \%[16 \%]$ & 0 & $7 \%$ pneumothorax \\
\hline $\operatorname{Diaz}^{34}$ & Thoracic & Pediatric & 31 & $1(1-3)$ & na & na & $3.2 \%$ pneumothorax \\
\hline Salazar-Riojas ${ }^{35}$ & Thoracic & Pediatric & 22 & $1(1-2)$ & 0 & 0 & none \\
\hline This study & Thoracic & Pediatric & 19 & $2(1-4)$ & $37 \%$ [24\%] & $6 \%[5.3 \%]$ & $5.2 \%$ hematoma \\
\hline Goldberg $^{36}$ & Thoracic & Adult & 75 & $1(1-6)$ & $16 \%$ & na & $\begin{array}{l}1.3 \% \text { pneumothorax } \\
1.3 \% \text { cardiac tamponade } \\
50 \% \text { thrombolytic therapy } \\
2.3 \% \text { procedure aborted }\end{array}$ \\
\hline Alegre $^{37}$ & Thoracic & Adult & 110 & $2(1-13)$ & $1.8 \%$ & na & $\begin{array}{l}1 \% \text { pneumothorax } \\
3.6 \% \text { infection }\end{array}$ \\
\hline Meisenberg $^{38}$ & Thoracic & Adult & 156 & na & $10.2 \%$ & na & $\begin{array}{l}3.6 \% \text { pneumo/hemothorax } \\
5.7 \% \text { thrombosis } \\
7 \% \text { infection }\end{array}$ \\
\hline $\operatorname{Hahn}^{39}$ & Thoracic & Adult & 153 & $4(2-12)$ & $5.2 \%[1.1 \%]$ & na & $\begin{array}{l}5 \% \text { thrombosis } \\
3 \% \text { infection } \\
2 \% \text { hematoma } \\
0.6 \% \text { pneumothorax }\end{array}$ \\
\hline Papadimitriou $^{40}$ & Thoracic & Adult & 72 & $1(1-2)$ & $6 \%[5.3 \%]$ & na & na \\
\hline $\operatorname{Reik}^{24,41 \mathrm{~d}}$ & Thoracic & Adult & 88 & $2(1-5)$ & $21 \%[13 \%]^{\mathrm{d}}$ & na & na \\
\hline
\end{tabular}

${ }^{\mathrm{a}}$ The median (range) of HPCC procedures performed.

${ }^{\mathrm{b}}$ The percent patients and [\% HPCC procedures] with documented CVC-related AE. Flow-AE and bleeding AE refer to occlusion and bleeding during leukapheresis. Other AE include $\mathrm{AE}$ associated with catheter insertion, catheter removal, infection and thrombosis.

${ }^{c}$ na, not available.

${ }^{\mathrm{d}}$ Reik et al. documents a $13 \%$ occlusion rate among 88 patients. ${ }^{41}$ A subsequent publication from the same group states that all the documented flow-related $\mathrm{AE}$ were in patients with subclavian CVC. ${ }^{24}$

prompting them to use a soft leg splint to immobilize patients. ${ }^{11}$ Sevilla et al. noted hematoma $(8 \%)$ and bleeding $(25 \%)$ in 12 children under $<10 \mathrm{~kg} .{ }^{31}$ Kanold et al. reported overall good performance in 14 children $<15 \mathrm{~kg}$, although one patient developed an abscess. ${ }^{43}$ Bolan et al. used femoral CVC in $80 \%$ (31/38) of pediatric patients, with serious 
bleeding and hematoma formation in one patient who underwent LVL (5 BV) with heparin anticoagulation. ${ }^{30}$ In pediatric ICU patients, similar rates of bleeding (5-9\%) and hematoma (3\%) have been reported, although the incidence of catheter obstruction and thrombosis were higher (11$28 \%)^{9,10}$

We also examined femoral CVC performance over time for the entire population, as well as individual patients. In general, the mean FE was stable over the course of AHPCC, despite significant day-day variability in individual patients. Two patients required reversal of arterial and venous lines, which has been reported to increase recirculation approximately three-fold during dialysis. ${ }^{44,45}$ and decrease CD34-FE in A-HPCC. ${ }^{30}$ This was a major concern since femoral CVC have a higher base-rate of recirculation relative to thoracic CVC. ${ }^{46,47}$ Although both patients experienced a decrease in CD34-FE (22\%, 60\%), it is difficult to attribute the decrease to recirculation given the normal intrapatient variation observed in our patient cohort.

One interesting observation was the apparent drop in CD34-FE 12-24 $\mathrm{h}$ after receiving plerixafor in many patients. The findings were unexpected and are difficult to explain. Plerixafor is not considered prothrombotic or proinflammatory. ${ }^{48}$ In animal models, plerixafor can moderate inflammatory immune disorders, decrease fibrosis, and promote revascularization. ${ }^{49}$ However, plerixafor is associated with an increase in peripheral WBC counts that is independent and synergistic with G-CSF. ${ }^{48,49}$ The latter could theoretically impact CD34-FE due to the inverse exponential relationship between peripheral $\mathrm{WBC}$ and CD34-FE. ${ }^{18,50,51}$ In adult myeloma patients, peripheral WBC $>20-35 \mathrm{~K}_{\mu} \mathrm{L}^{-1}$ have been reported to depress CD34-FE, ${ }^{18,50}$ with some centers dictating a slower inlet rate at high peripheral WBC. ${ }^{51}$ In our limited pediatric series, most (7/9, Figure 3) patients had relatively modest peripheral WBC counts after plerixafor

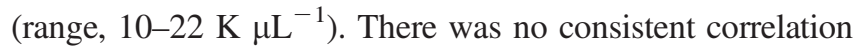
between CD34-FE, peripheral WBC, or platelet count in these patients.

Our study shows the safety and good performance characteristics of femoral double-lumen polyurethane dialysis CVC in pediatric HPCC, especially in small and very young children. Access options used in this population include double and single lumen CVCs (silicon, polyurethane), radial artery catheters, and PIVs. ${ }^{1,4,33,52,53}$ Long-term, silicone CVCs are soft and would appear to be an attractive option in young children; however, they are prone to collapse under the negative pressure encountered during automated apheresis. ${ }^{1}$ Moreover, the risk of mechanical occlusion increases with decreasing lumen size, leading one investigator to recommend a 10 French or larger when using silicone CVCs. ${ }^{1}$ Fishmeister et al. compared long-term, tunneled, silicone CVCs (7-12 French) in 51 children and young adults under- going A-HPCC. ${ }^{4}$ Low inlet rates, reversal of draw and return lines, and line occlusion occurred in $28 \%$ of patients and $20 \%$ of procedures. Furthermore, patients still required PIV for return to avoid recirculation due to the close proximity of the draw and return lumens. Likewise, Orbach observed a 23\% occlusion rate during HPCC using pre-existing thoracic CVC. ${ }^{33}$ Finally, long-term, CVCs have an increasing risk of thrombosis, dysfunction and infection over time. ${ }^{5-8}$ As noted earlier, the only case of true bacterial infection and product contamination in our pediatric population was associated with a tunneled, subclavian CVC.

Femoral CVCs may have other advantages in young children relative to subclavian and internal jugular CVC. Subclavian lines have a lower success rate for insertion (87\% versus 94\% femoral CVC), with $26-40 \%$ of children experiencing an AE. ${ }^{9,10}$ Furthermore, bleeding complications arising during cannulation and insertion of subclavian and internal jugular lines can be difficult to manage, leading to hemothorax, cardiac tamponade and even death. ${ }^{8}$ Other complications of thoracic CVC are pneumothorax, cutaneous emphysema, air embolism, brachial plexus injury, and cardiac arrhythmias (Table 5). ${ }^{1,3,32-39,54}$ As noted by Gorlin, ${ }^{1}$ very young children may be particularly susceptible to cardiac arrhythmias due to their small anatomy relative to catheter length, leading to a significant risk of the tip extending deep into the right atrium with mechanical irritation of the sinoatrial node. ${ }^{1,3}$ Finally, thoracic CVC are associated with greater intraprocedure decreases in blood pressure during apheresis procedures. ${ }^{55}$

Subclavian CVCs also have $\sim 15 \%$ incidence of catheter malposition and dysfunction. ${ }^{9,10,56}$ with flow-related issues in 3-64\% of patients (Table 5). This is particularly true of left subclavian CVCs, which have a 16-50\% AE rate during A-HPCC and account for $19 \%$ of severe procedure-related $\mathrm{AE}$ at our institution. ${ }^{15,38,57-60}$ The increased length associated with left subclavian lines inherently increases resistance to flow and the potential for anatomic obstruction. ${ }^{57}$ The distal tip can either adhere along the lateral superior vena cava with intermittent occlusion, or reflect back into the left brachial cephalic vein with intravascular knotting., ${ }^{4,57}$

In summary, we report our experience using short-term femoral CVC for A-HPCC in young children. Femoral CVC provided adequate venous access with few flow-related alarms or complications when compared to thoracic CVC in our pediatric population. Our experience with femoral CVC for A-HPCC is equivalent or better than that reported in adults. ${ }^{24-29}$ Potential disadvantages of femoral CVC are mobility restrictions due to risk of catheter kinking, breaking or disconnection; vessel injury, thrombosis, and infection. ${ }^{11,61}$ Studies in adults, however, have shown that patients with femoral lines can undergo limited physical activities (sitting, standing, limited walking) without CVC- 
related $\mathrm{AE} .{ }^{61}$ In addition, femoral and thoracic CVC placement in young children typically require anesthesia, ${ }^{42,62}$ which has a reported 2-3\% complication rate in this population, ${ }^{62}$ although none of our patients experienced anesthetic complications associated with femoral CVC insertion. Inherent limitations of our findings is the single institution, retrospective study design. Nonetheless, to our knowledge, this is the first study to report an in-depth analysis of femoral CVC performance and outcomes in pediatric A-HPCC in a moderately large cohort of young children.

\section{ACKNOWLEDGMENTS}

The authors thank the nurses of the apheresis unit (APU) for their care and support of patients. The authors also thank the staff of the Cell Therapy Laboratory, who are responsible for data entry and management.

\section{REFERENCES}

[1] Gorlin JB, Humphreys D, Kent P, et al. Pediatric large volume peripheral blood progenitor cell collections from patients under 25 kg: a primer. J Clin Apheresis. 1996;11:195-203.

[2] Moog R. Peripheral blood stem cell collection in children: management, techniques and safety. Transf Aph Sci. 2010;43: 203-205.

[3] Jones HG, Bandarenko N. Management of the therapeutic apheresis patient. In: McLeod BC, Price TH, Weinstein R, eds. Apheresis: Principles and Practice. 2nd ed. Bethesda, MD: AABB Press; 2003:253-282.

[4] Fishmeister G, Witt V, Zaunschirm HA, et al. Permanent tunneled silicone central venous catheters for autologous PBPC harvest in children and young adults. Bone Marrow Transplant. 2000;26:781-786.

[5] Lazarus HM, Trehan S, Miller R, Fox RM, Creger RJ, Raaf JH. Multi-purpose silastic dual-lumen central venous catheters for both collection and transplantation of hematopoietic progenitor cells. Bone Marrow Transplant. 2000;25:779-785.

[6] Restpro A, Devore P, Encarnacion CE, et al. Performance of a hybrid central venous catheter utilized for both peripheral blood stem cell harvest and transplant support of patients undergoing autologous peripheral blood stem cell transplantation. Bone Marrow Transplant. 2002;30:389-395.

[7] Choi SW, Chang L, Hanauer DA, et al. Rapid reduction of central line infections in hospitalized pediatric oncology patients through simple quality improvement methods. Pediatr Blood Cancer. 2013;60:262-269.

[8] Wiegering V, Schmid S, Andres O, et al. Thrombosis as a complication of central venous access in pediatric patients with malignancies. BMC Hematol. 2014;14:18. Available at: http:// www.biomedcentral.com/2052-1839/14/18.

[9] Karapinar B, Cura A. Complications of central venous catheterization in critically ill children. Pediatr Internl. 2007;49:593599.
[10] Casado-Flores J, Barja J, Martino R, Serrano A, Valdivielso A. Complications of central venous catheterization in critically ill children. Pediatr Crit Care Med. 2001;2:57-62.

[11] Yocco M, Healy D, Barnes Y, et al. Pediatric pheresis leg splint immobilization to increase efficiency of stem cell collection and control femoral pheresis catheter malfunctions [abstract]. Biol Blood Marrow Transplant. 2008;14(S):151.

[12] Merrer J, De Jonghe F, Lefrant J-Y, et al. Complications of femoral and subclavian venous catheterization in critically ill patients: a randomized trial. JAMA. 2001;286:700-707.

[13] Venkataraman ST, Thompson AE, Orr RA. Femoral vascular catheterization in critically ill infants and children. Clin Pediatr (Phila). 1997;36:311-319.

[14] Cooling L, Hoffmann S, Yamada C, Levine J, Yanik G, Davenport R. Impact of blood prime on pediatric autologous peripheral blood stem cell collection [abstract]. J Clin Apheresis. 2015;30:71-72.

[15] Cooling L, Hoffmann S, Webb D, et al. Procedure-related complications and adverse events associated with pediatric autologous peripheral blood stem cell collection. J Clin Apheresis. 2017;32:35-48.

[16] University of Michigan. Venous access devices: assessment and care. Available at: www.med.umich.edu/i/nursing/policies/ VAgrid.pdf

[17] Cooling L, Bombery M, Hoffmann S, et al. The impact of recent vincristine on human hematopoietic progenitor cell collection in pediatric patients with central nervous system tumors. Transfusion. 2014;54:2004-2014.

[18] Cooling L, Hoffmann S, Herrst M, Muck C, Armelagos H, Davenport R. A prospective randomized trial of two popular mononuclear cell collection sets for autologous peripheral blood stem cell collection in multiple myeloma. Transfusion. 2010;50: 100-119.

[19] Sutherland DR, Anderson L, Keeney M, et al. The ISHAGE guidelines for $\mathrm{CD} 34+$ cell determination by flow cytometry. International society for haematotherapy and graft engineering. J Hematother. 1996;5:213-226.

[20] Food and Drug Administration. Code of Federal Regulations, General Biological Product Standards: 21 CFR 610.12. 2011.

[21] Ford CD, Pace N, Lehman C. Factors affecting the efficiency of collection of CD34-positive peripheral blood stem cells by a blood cell separator. Transfusion. 1993;38:1046-1050.

[22] Benjamin RJ, Linsley L, Fountain D, et al. Preapheresis peripheral blood CD34+ mononuclear cell counts as predicators of progenitor cell yield. Transfusion. 1997;37:79-85.

[23] Hinds PS, Quargnent A, Gattuso J, et al. Comparing the results of coagulation tests on blood drawn by venipuncture and through heparinized tunneled venous access devices in pediatric patients with cancer. Onc Nursing Forum. 2002;29:E26-E34. DOI: 10.1188/02.ONF.E26-E34.

[24] Shariatmadar S, Noto TA. Femoral vascular access for largevolume collection of peripheral blood progenitor cells. J Clin Apheresis. 1998;13:99-102.

[25] Moreiras-Plaza M, Albo C, Ares C. Efficacy and safety of femoral vascular access for peripheral blood stem cell (PBSC) collection. Bone Marrow Transplant. 2004;33:347-350. 
[26] Adorno G, Zinno F, Bruno A, et al. Femoral catheters: safety and efficacy in peripheral blood stem cell collection. Int $J$ Artif Organs. 1999;22:710-712.

[27] Saif MW, Leitman SF, Cusack G, et al. Thromboembolism following removal of femoral venous apheresis catheters in patients with breast cancer. Ann Oncol. 2004;15:1366-1372.

[28] Donmez A, Cagirgan S, Tombuloglu M. Short-term femoral venous dialysis catheters for autologous peripheral blood progenitor cell collection: retrospective evaluation in 276 catheter practice from a single center. Transf Apher Sci. 2007;37:165169.

[29] Sohn SK, Kim JW, Chae YS, et al. Large-volume leukapheresis using femoral venous access for harvesting peripheral blood stem cells with the Fenwal CS3000 Plus from normal healthy donors: predicators of CD34+ cell yield and collection efficiency. J Clin Apheresis. 2003;18:10-15.

[30] Bolan CD, Yau YY, Cullis HC, et al. Pediatric large-volume leukapheresis: a single institution experience with heparin versus citrate-based anticoagulant regimens. Transfusion. 2004;44:229238.

[31] Sevilla J, Fernandez Plaza S, Conzalez-Vicent MM, et al. PBSC collection in extremely low weight infants: a single-center experience. Cytotherapy. 2007;9:356-361.

[32] Madero L, Diaz MA, Benito A, Villa M, Valdivielso A. Nontunneled catheters for the collection and transplantation of peripheral blood stem cells in children. Bone Marrow Transplant. 1997;20:53-56.

[33] Orbach D, Hojjat-Assari S, Doz F, et al. Peripheral blood stem cell collection in 24 low-weight infants: experience of a single centre. Bone Marrow Transplant. 2003;31:171-174.

[34] Diza MA, Villa M, Alegre A, et al. Collection and transplantation of peripheral blood progenitor cells mobilized by G-CSF alone in children with malignancies. Br J Haematol. 1996;94:148-154.

[35] Salazar-Riojas R, Garcia-Lozano JA, Valdes-Galvan M, et al. Effective collection of peripheral blood stem cells in children weighting 20 kilogram or less in a single large-volume apheresis procedure. J Clin Apheresis. 2015;30:281-287.

[36] Goldberg SL, Mangan KF, Klumpp TR, et al. Complications of peripheral blood stem cell harvesting: review of 554 PBSC leukaphereses. J Hematother. 1995;4:85-90.

[37] Alegre A, Requena MJ, Fernandez-Villalta MJ, et al. QuintonMahurkar catheter as short-term central venous access for PBSC collection: single-center experience of 370 aphereses in 100 patients. Bone Marrow Transplant. 1996;18:865-869.

[38] Meisenberg BR, Callaghan M, Sloan C, Sampson L, Miller WE, McMillan R. Complications associated with central venous catheters used for the collection of peripheral blood progenitor cells to support high-dose chemotherapy and autologous stem cell rescue. Support Care Cancer. 1997;5:223-227.

[39] Hahn U, Goldschmidt h, Salwender H, Haas R, Hunstein W. Large-bore central venous catheters for the collection of peripheral blood stem cells. J Clin Apheresis. 1995;10:12-16.

[40] Papadimitriou C, Dimopoulos MA, Kouvelis V, et al. Non-cryopreserved peripheral blood progenitor cells collected by a single very large-volume leukapheresis: a simplified and effective pro- cedure for support of high-dose chemotherapy. J Clin Apheresis. 2000;15:236-241.

[41] Reik RA, Noto TA, Fernandez HF. Safety of large-volume leukapheresis for collection of peripheral blood progenitor cells. J Clin Apheresis. 1997;12:10-13.

[42] Pulsipher MA, Levine JE, Hayashi RJ, et al. Safety and efficacy of allogeneic PBSC collection in normal pediatric donors: the pediatric and marrow transplant consortium experience (PBMTC) 1996-2003. Bone Marrow Transplant. 2005;35:361367.

[43] Kanold J, Halle P, Berger M, et al. Large-volume leukapheresis procedure for peripheral blood progenitor cell collection in children weighing $15 \mathrm{~kg}$ or less: efficacy and safety evaluation. Med Pediatr Oncol. 1999;32:7-10.

[44] Hassan HA, Frenchie DL, Bastani B. Effect of reversal of catheter ports on recirculation: comparison of the PermCath with Tesio twin catheter. Asaio J. 2002;48:316-319.

[45] Atapour A, Mosakazemi M, Mortazavi M, Beigi A, Shahidi S. Access recirculation in jugular venous catheter in regular and reversed lines. IJKD. 2008;2:91-94.

[46] Little MA, Conlon PJ, Walshe JJ. Access recirculation in temporary hemodialysis catheters as measured by the saline dilution technique. Am J Kidney Dis. 2000;36:1135-1139.

[47] Sefer S, Kes P, Degoricija V, Heinrich B, Vrsalovic M. Recirculation of urea and dialysis efficiency using dual-lumen dialysis catheters in various locations: may the venous lumen of the catheter be used as the arterial lumen and vice versa? Lijec Vjesn. 2003;125:1-5.

[48] Blum A, Childs RW, Smith A, et al. Targeted antagonism of CSCR4 mobilizes progenitor cells under investigation for cardiovascular disease. Cytotherapy. 2009;11:1016-1019.

[49] Fricker SP. Physiology and pharmacology of plerixafor. Transfus Med Hemother. 2013;40:237-245.

[50] Gidron A, Verma A, Doyle M, et al. Can the stem cell mobilization technique influence CD34+ cell collection efficiency of procedures in patients with hematologic malignancies? Bone Marrow Transplant. 2005;35:243-246.

[51] Burgstaler JE, Pineda AA, Winter JL. Effects of high whole blood flow rates and high peripheral WBC on CD34+ yield and cross-cellular contamination [abstract]. Cytotherapy. 2003;5:446.

[52] Takaue Y, Kawano Y, Abe T, et al. Collection and transplantation of peripheral blood stem cells in very small children weighing $20 \mathrm{~kg}$ or less. Blood. 1995;86:372-380.

[53] Bambi F, Fontanazza S, Messeri A, et al. Use of percutaneous radial artery catheter for peripheral blood progenitor cell collection in pediatric patients. Transfusion. 2003;43:254-258.

[54] Grifols JR, Ferra C, Sancho JM, Pujol M, Ribera JM. A case of non-lethal pulmonary air embolis after leukapheresis catheter removal. J Clin Apheresis. 2005;20:93-94.

[55] Yeh JH, Chen WH, Chiu HC. Hemodynamic effects of the different vascular accesses used for double-filtration plasmapheresis. J Clin Apheresis. 2001;16:125-129.

[56] Unal AE, Bayar S, Arat M, Ilhan O. Malpositioning of Hickman catheters, left versus right sided attempts. Transf Aph Sci. 2003;28:9-12. 
[57] Tsai Y-F, Ku Y-H, Chen S-W, Huang W-T, Lu C-C, Tsao C-J. Right and left subclavian Port-A-Cath systems: comparison of complications. Eur Surg Res. 2012;49:66-72.

[58] Craft PS, May J, Doriogo A, Hoy C, Plant A. Hickman catheters: left-sided insertion, male gender and obesity are associated with an increased risk of complications. Aust N Z J Med. 1996;26:33-39.

[59] Dolan K, Blume C, Capone C, Cooling L, Champney D, Henry JB, Huebner P, Sisson S. Anatomic placement effects the performance of the Neostar Pheres-Flow Catheter [abstract]. J Clin Apher. 2000;15:A69.

[60] Sheldon S, Hoffmann S, Schrag E, Meade M, Cooling L. Improving clinical documentation of procedure related complications in peripheral blood stem cell collection [abstract]. Transfusion. 2010;50S:274A.

[61] Perme C, Nalty T, Winkelman C, Nawa RK, Masud F. Safety and efficacy of mobility interventions in patients with femoral catheters in the ICU: a prospective observational study. Cardiopulmonary Phys Ther J. 2013;24:12-17.
[62] Fitzgerald RK, Yu JC, Rajasekaran S, et al. Cost and safety of pediatric intensive care physician-placed broviac catheters. Ped Crit Care Med. 2014;15:71-76.

\section{SUPPORTING INFORMATION}

Additional Supporting Information may be found in the online version of this article.

How to cite this article: Cooling L, Hoffmann S, Webb D, Yamada C, Davenport R, Choi SW. Performance and safety of femoral central venous catheters in pediatric autologous peripheral blood stem cell collection. J Clin Apher. 2017;32:501-516. https://doi.org/ 10.1002/jca. 21548 